Www.jmscr.igmpublication.org

Impact Factor (SJIF): 6.379

Index Copernicus Value: 79.54

ISSN (e)-2347-176x ISSN (p) 2455-0450

crossrefDOI: https://dx.doi.org/10.18535/jmscr/v6i9.100

Journal Of Medical Science And Clinical Research

IGM Publication

An official Publication of IGM Publication

\title{
A Comparative Study of Effect of Single-Dose Prophylactic Antibiotic versus Conventional Antibiotic Therapy in Selected Clean Surgical Cases in A Tertiary Care Centre
}

\author{
Authors \\ Dr M Basavarajappa ${ }^{1}$, Dr Ananth $S$ Mathad ${ }^{2}$, Dr Deepak $\mathbf{G}^{3}$ \\ ${ }^{1}$ Professor, Dept of General Surgery, SSIMS \& RC, Davangere \\ ${ }^{2}$ General Surgeon, Davangere \\ ${ }^{3}$ Post Graduate, Dept of General Surgery, SSIMS\&RC, Davangere
}

\begin{abstract}
This tertiary care hospital based prospective study was performed to compare the effect of single dose prophylactic versus conventional antibiotic therapy in clean surgical cases operated in SSIMS\&RC, Davangere. A total of 100 cases were studied, male patients were more compared to females with ratio of 3:2, with mean age of 42.7 years, all clean surgical cases were operated, with highest being inguinal hernia $31 \%$. In this study $6 \%$ of cases in group-II and $2 \%$ case in group-I had postoperative infection, with most common organism isolated being staphylococcus aureus. This study highlights the judicious use of prophylactic antibiotics in order to prevent emergence of antibiotic resistance and to reduce prolonged hospital stay and cost incurred due to antibiotics.

Keywords: Antibiotic prophylaxis, antibiotic utilisation, clean surgical cases, cost-effective.
\end{abstract}

\section{Introduction}

Surgical site infections (SSIs) are infections of the incision or organ or space that occur after surgery. SSIs are the most common healthcare-associated infection, accounting for $31 \%$ of all HAIs among hospitalized patients ${ }^{1}$. The CDC healthcareassociated infection (HAI) prevalence survey found that there were an estimated 157,500 surgical site infections associated with inpatient surgeries in $2011^{2}$. NHSN data included 16,147 SSIs following 849,659 operative procedures in all groups reported, for an overall SSI rate of $1.9 \%$ between $2006-2008^{3}$. A $19 \%$ decrease in SSI related to 10 select procedures was reported between 2008 and $2013^{4}$. Public reporting of process, outcome, and other quality improvement measures is now required, and reimbursements for treating SSIs are being reduced or denied. It has been estimated that approximately half of SSIs are preventable by application of evidence-based strategies.

SSIs are associated with considerable morbidity and it has been reported that over one-third of postoperative deaths are related, at least in part, to $\mathrm{SSI}^{5}$. SSI can double the length of time a patient stays in hospital and thereby increase the costs of health care. Additional costs attributable to SSI of between $£ 814$ and $£ 6626$ have been reported depending on the type of surgery and the severity of the infection ${ }^{6,7}$. The main additional costs are 
related to re-operation, extra nursing care and interventions, and drug treatment costs. The indirect costs, due to loss of productivity, patient dissatisfaction and litigation, and reduced quality of life, have been studied less extensively.

Patients with SSIs are more likely to require readmission to hospital or intensive care unit (ICU) treatment, and are at higher risk of death, than those without such infections.

Continuing vigilance is therefore required to minimise the incidence of such infections. This requires a systematic approach, with attention to multiple risk factors related to the patient, the procedure, and the hospital environment.

\section{Objective}

To assess the effect of single-dose prophylactic antibiotic versus conventional antibiotic therapy in selected clean surgical cases.

\section{Materials \& Methods}

This study was conducted as a randomized casecontrol prospective study in the Department of Surgery in S S Institute of medical sciences and research centre, Davangere from 2017 march to 2018 march. Totally 100 patients admitted for clean surgery in our hospital without any comorbid conditions were included in this study.

Patients were selected using the inclusion criteria of all patients undergoing elective clean procedures, i.e, an uninfected operative wound In which no inflammation is encountered and the respiratory, alimentary, genital, or uninfected urinary tract is not entered. Surgeries included are thyroid surgeries, hernia repair, varicose vein surgeries, soft tissue cysts excision, hydrocele surgeries, circumcision etc

Exclusion criteria were patients Age less than 18 and more than 65 years, Coexisting diabetes mellitus, hypertension, pulmonary koch's and immune-compromised conditions, Pregnancy and lactating mothers, Contaminated surgeries, Allergic to cephalosporins, Refusal to give consent .
The Use of Antibiotics are Predetermined as Follows

Study Group: One dose of $1 \mathrm{~g}$ injection Cefazolin IV after test dose at the time of incision and no more antibiotics are prescribed.

Control Group: No pre-operative antibiotic given. In the post-operative ward for the first 3 days IV antibiotics are given as follows:

Inj ciprofloxacin $200 \mathrm{mg}$ IV bd, Inj metronidazole $500 \mathrm{mg}$ IV tid,

Inj amikacin $500 \mathrm{mg}$ IV bd.

The ethical clearance was obtained from ethical committee, S S institute of medical sciences \& Research centre, Davangere. Patients undergoing elective clean surgical cases were randomly allocated a group into random number table using computer generated software www.randomization.com) into two groups where, Group I will be given preoperative Prophylactic single dose antibiotic (Cephazolin antibiotics $1 \mathrm{~g}$ IV) at the time of incision and Group II Injection ciprofloxacin $200 \mathrm{mg}$ IV bd, Injection metronidazole $500 \mathrm{mg}$ IV tid, Injection amikacin $500 \mathrm{mg}$ IV bd for 3 days.

Under all aseptic precautions and strict vigilance the surgery is conducted inpatients of both groups with no differences in surgical technique.

Post operatively analgesia is administered as a routine practice.

For the day care surgeries done under outpatient basis, oral analgesic tablet tramadol $50 \mathrm{mg}$ twice a day basis is prescribed as a routine hospital practice and discharged with advice regular follow up visits.

Apart from daily routine examination, patients are examined even on follow up visits for any complications of surgery and anaesthesia with an attention towards the surgical wound infection is given. General physical examination is conducted till the patient is discharged routinely to look for surgical site infection.

Surgical wound is examined on post-operative day 2, under aseptic precautions, to check for erythema, raised temperature, purulent discharge, in duration, edema which suggest acute 
inflammation confirming infection at the surgical site. After Day 2 wound examination, wounds are kept open to air with no dressing Pad on the surgical wound, if no infection is noted.

Wound examination is repeated again every consecutive day until Day 7, Day 30 and Day 60 and checked again for signs and symptoms of wound infection. suture removal is done on Day 8 under aseptic precautions after confirming no infection is present, when symptoms and signs of infection are present on routine wound examination, pus is taken for Gram's staining and Culture and sensitivity testing in absolute asepsis. Immediately, empirically antibiotics are started with Injection Cephazolin 1gram intravenously twice a day till the report of Culture and Sensitivity is obtained. Later, depending on the report, the sensitive antibiotic to the organism cultured is started to resolve the infection.

Complete resolution of infection is confirmed with absence of pus discharge from the wound, absent erythema surrounding the wound absence of induration, edema and raised temperature on wound examination.

\section{Observation \& Results}

The study group consisted of 100 cases of clean surgical cases those underwent in S S institute of medical sciences and research centre divided into two groups. Analyses of the results obtained after the completion of study under various parameters are done.

Among all the 100 cases, the sex distribution was analysed

Graph 1: Sex Distribution among All Cases

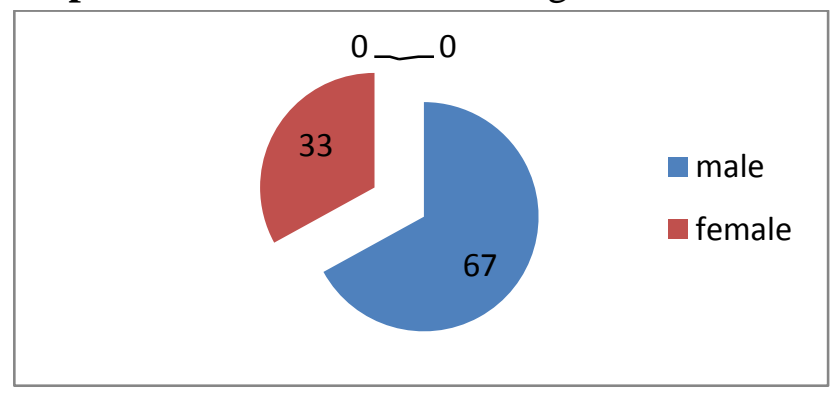

Among 100 cases, 67 were male patients and remaining 33 cases in female population. In both the groups, majority of the cases were seen in male group with male to female ratio $3: 2$

\section{Infection Grading in the Ward}

Based on the Southampton scoring system on the $3 \mathrm{rd}$, 5th, and 7th post-operative period the wounds were inspected and the infection grades are noted.

Table 1: Age Wise Distribution in Both Groups

\begin{tabular}{|l|c|c|c|}
\hline AGE & $\begin{array}{c}\text { Group I } \\
\text { N(\%) }\end{array}$ & $\begin{array}{c}\text { Group II } \\
\text { N(\%) }\end{array}$ & $\begin{array}{c}\text { Total } \\
\text { N }\end{array}$ \\
\hline$<\mathbf{2 0}$ & $2(4)$ & $4(8)$ & 6 \\
\hline $\mathbf{2 1 - 3 0}$ & $7(14)$ & $8(16)$ & 15 \\
\hline $\mathbf{3 1 - 4 0}$ & $11(22)$ & $17(34)$ & 28 \\
\hline $\mathbf{4 1 - 5 0}$ & $9(18)$ & $7(14)$ & 16 \\
\hline $\mathbf{5 1 - 6 0}$ & $17(34)$ & $7(14)$ & 24 \\
\hline $\mathbf{6 1 - 6 5}$ & $4(8)$ & $7(14)$ & 11 \\
\hline
\end{tabular}

Age wise distribution was studied in both groups from 18 years to 65 years as considered in inclusion criteria. maximum number of cases were seen in the age group 31-40 years with 28 cases and least in $<20$ years with only 6 cases.

In group I , most of the cases were seen in 51-60 years age group with $34 \%$ and least in $<20$ years age group with $4 \%$. the mean age was 42.7 according to the study.

In group II the mean age calculated was 42.47 . maximum cases were seen in the age group of 31 40 years with $34 \%$ cases and least in <20 years age group with $8 \%$ cases which match with the overall figures.

Table 2: Disease Wise Distribution of the Cases

\begin{tabular}{|l|c|c|c|}
\hline Diseases & Group I & Group II & Total \\
\hline Hernia & 16 & 15 & 31 \\
\hline Varicose Veins & 04 & 05 & 09 \\
\hline Genitalia & 07 & 06 & 13 \\
\hline Breast & 08 & 05 & 13 \\
\hline Thyroid & 00 & 02 & 02 \\
\hline Benign Lesions & 15 & 17 & 32 \\
\hline Total & 50 & 50 & 100 \\
\hline
\end{tabular}

The cases those operated are divided into many groups for the ease of study.

Hernia was operated in Second highest number under this study as an individual disease. Total 
number of 31 cases is taken into studies, 16 in group I and 15 in Group II.

Varicose veins was also operated and taken into study with total number of 09 cases with 04 in Group I and 05 in Group II.

Diseases limited to external genitalia were considered for the study. Total of 13 cases were taken into study with 07 cases in Group I and 06 cases in fitting into Group II.

Fibro adenoma of the breast was commonly seen pertaining to breast disease. $\ln$ total 13 cases were operated, 08 cases in Group I and other 05 cases falling in Group II.

2 cases of Multi Nodular Goiter was taken into study with both cases falling into Group II

Benign lesions generally form the bulk of the diseases in general surgery forming largest group. In our study, total of 32 cases were operated involving lipoma, Lymphnode, corn and ectopic salivary gland. 15 cases were operated in the Group Iand remaining 17 cases in the other group.

Table 3: Laterality of Inguinal Hernia in the Study

\begin{tabular}{|l|c|c|c|}
\hline Inguinal Hernia & Right & Left & Bilateral \\
\hline Group I & 09 & 06 & 01 \\
\hline Group II & 10 & 05 & 00 \\
\hline
\end{tabular}

Inguinal hernias were considered for the study as it falls under clean cases.

All the three kinds of hernias with laterality were considered in the study. Right sided formed the highest number with 09 cases in group I followed by 06 cases on the left side and single case of bilateral inguinal hernia.

In group II, again the right sided were more common with a total of 10 cases followed by the left sided inguinal hernia with 05 cases.

Table 4: Varicose Veins Cases Distribution

\begin{tabular}{|l|c|c|}
\hline Varicose Veins & Right & Left \\
\hline Group I & 3 & 1 \\
\hline Group II & 2 & 3 \\
\hline
\end{tabular}

Varicose veins with sapheno-femoral incompetence with multiple perforators were part of study where Trendenlenbergs procedure with stripping and perforator ligation was done according to the study design.

Among all the 09 cases, 04 cases were seen in Group I with 03 in the right side and 01 case in the left.

In the Group II, 02 were operated on the right side and 3 on the left side with similar techniques under same conditions.

Table 5: Distribution of Benign Lesions

\begin{tabular}{|l|c|}
\hline Disease & Number \\
\hline Lipoma & 14 \\
\hline Sebaceous Cyst & 12 \\
\hline Lymphadenopathy & 2 \\
\hline Ectopic Salivary Gland & 1 \\
\hline Corn & 3 \\
\hline
\end{tabular}

Benign lesions formed the major part of the study with 32 cases. five types of lesions were seen in the study. majority being lipoma including fibrolipoma and axillary lipoma accounting to 14 cases followed by 12 cases as sebaceous cyst involving sebaceous cyst over scrotum , 3 corn lesions, 2 lymph node swellings and 1 ectopic salivary gland.

Table 6: Disease Distribution Related to Genitalia

\begin{tabular}{|l|c|c|c|}
\hline Disease & Group I & Group II & Total \\
\hline Hydrocele & 4 & 3 & 7 \\
\hline Phimosis & 1 & 1 & 2 \\
\hline Epididymal Cyst & 1 & 0 & 1 \\
\hline
\end{tabular}

Diseases related to the external genitalia i.e scrotum and penis was considered in the study involving hydrocele, phimosis, and epididymal cyst.

In group I, 4 cases of hydrocele, 2 cases of phimosis and 1 case of epididymal cyst were operated in group II , 3 cases of hydrocele and phimosos each was taken into study.

According to the criteria, none of the procedures extended beyond 120 minutes. maximum number of cases had a length ranging in the group of 30 to 60 minutes with $52 \%$. less than 30 minutes group had $41 \%$ and 60 to 120 minutes group with remaining $7 \%$. 
Table 12: Frequency of Post-Operative Wound Infections

\begin{tabular}{|l|c|c|c|}
\hline Infection & $\begin{array}{c}\text { Present } \\
\mathbf{N}(\%)\end{array}$ & $\begin{array}{c}\text { Absent } \\
\mathbf{N}(\%)\end{array}$ & Total \\
\hline Group I & $1(2 \%)$ & $49(98 \%)$ & 50 \\
\hline Group Ii & $3(6 \%)$ & $47(94 \%)$ & 50 \\
\hline
\end{tabular}

According to the study design, wound examination was conducted on regular basis. in group I , $2 \%$ of cases were infected involving 1 case and in group II $6 \%$ cases were infected with 3 cases.

Table 13: Isolates from Wound Infections

\begin{tabular}{|l|c|c|}
\hline Organism & Number & Percentage \\
\hline Staphylococcus aureus & 3 & 75 \\
\hline E-Coli & 1 & 25 \\
\hline
\end{tabular}

Pus was sent for Culture and sensitivity in all the four cases that had infection.

A $75 \%$ case that is 3 cases had staphylococcus aureus was isolated and in other case Escherichia coli was the isolate obtained. Later according to the sensitivity report, the medications were given and patient was treated.

Repeat culture on 5th day of starting sensitivity based antibiotics from the infected wound site of all the 4 cases involved showed no growth with resolution of infection.

\section{Discussion}

This is a prospective study of 100 cases of clean surgical cases studied at S S institute of medical sciences and research centre, Davangere. The Clean surgery is where there is no break in the aseptic techniques used in the entire procedure starting from the preoperative preparations to the final discharge and regular follow up visits of the patient. there is no entry into the gastrointestinal tract, respiratory or the genitor-urinary tract strictly.

The use of prophylactic antibiotic in all surgical cases are advocated ever since, the concept of use of antibiotic pre-operatively to curtain and prevent wound infection was postulated by Bernard and Cole in $1964^{8}$.

Proper usage of antibiotics in patients undergoing surgery is necessary, otherwise misuse of potent antimicrobials lead to drug toxicity, super infections, colonization of wards by highly resistant microbes and healthcare cost.

Three uncontrolled observational studies showed that when antibiotics were given for surgical prophylaxis, there was an increased risk of the patients treated acquiring antibiotic resistant strains following treatment ${ }^{(9,10,11)}$

Chambers in their study recommended that first generation cephalosporin antibiotic the cefazolins are drugs of choice for the use of prophylactic antibiotics for the general surgical prophylaxis than the second or third generation cephalosporin $^{12}$.

Many studies have recommended the first dose of antibiotic to be given 30- $60 \mathrm{~min}$ prior to surgery, and long-acting antibiotic must be selected ${ }^{13}$.

Administration of prophylaxis more than 3 hours after start of the operation significantly reduces its effectiveness ${ }^{14}$.

A study by Erickson et al, in Tanzania showed that stap aureus was the most common isolate , followed by e.coli and klebsiella species where in our study to the organisms isolated are s.aureus followed by E.coli.

To find out the economical saving achieved with the right prophylaxis to prevent surgical wound infections, a study was done by Fernandez. A total of 5260 patients operated during 1990-93 were included. Making constant all variables, i.e immunodeficiency, incorrect healing, reoperated patients, type of surgery and wrong prophylaxis, the percentage of infection prevented by right prophylaxis and the cost was evaluated starting from the number of extra days of infection. The number of extra days of infection prevented during 4 years was 310, saving a total of 194 million pesetas (1.5 million dollars), due to right prophylaxis. Cost benefit ratio was $1 / 17$. Hence the right prophylaxis is of utmost importance in order to avoid the development of infections ${ }^{15}$.

Wound infection reported in literature for clean wound is between $1.5 \%$ and $4 \%{ }^{(16,17)}$. Our study shows a wound infection rate of $6 \%$ with conventional antibiotics and same $2 \%$ with prophylactic antibiotics. 
In our study, group II patients, hospital stay including the cost incurred on the antibiotics was more compared to other group.

A surgeon can either prevent or decrease the risk of postoperative wound infection by correcting the factors involved in the development of postoperative wound infection.

Prophylactic antibiotics are no substitute for good surgical practice including strict aseptic technique. Infection a clean operation is always due to exogenous bacteria i.e, exogenous contact from breaks in technique by operating team.

\section{Conclusion}

Single dose prophylactic antibiotic is sufficient in preventing wound infection in clean surgical cases. Prolonged administration of antibiotics is unnecessary and costlier. Decision to use prophylactic antibiotic therapy must be based on balancing possible benefits against adverse effects. Indiscriminate use of antibiotics should be discouraged, as it leads to emergence of antibiotic resistant strains of organisms.

\section{References}

1. Magill, S.S., et al., "Prevalence of healthcare-associated infections in acute care hospitals in Jacksonville, Florida". Infection Control Hospital Epidemiology, 33(3): (2012): 283-91.

2. Magill, S.S., et al., "Multistate pointprevalence survey of health careassociated infections". New England Journal of Medicine, 370(13): (2014): 1198-1208.

3. Mu, Y., et al., "Improving risk-adjusted measures of surgical site infection for the national healthcare safety network". Infection Control Hospital Epidemiology, 32(10): (2011): 970-86.

4. CDC National and State HealthcareAssociated Infections Progress Report, published March 2016, available from: www.cdc.gov/hai/surveillance/progressreport/index.html
5. Astagneau P, Rioux C, Golliot F, et al. Morbidity and mortality associated with surgical site infections: results from the 1997-1999 INCISO surveillance. Journal of Hospital Infection. 2001;48:267-74

6. Coello R, Charlett A, Wilson J, et al. Adverse impact of surgical site infections in English hospitals. Journal of Hospital Infection. 2005;60:93-103.

7. Plowman R, Graves N, Griffin MA, et al. The rate and cost of hospital-acquired infections occurring in patients admitted to selected specialties of a district general hospital in England and the national burden imposed. Journal of Hospital Infection. 2001;47:198-209.

8. Bernard HR, Cole WR. The prophylaxis of surgical infection, the effect of prophylactic antimicrobial drugs on the incidence of infection following potentially contaminated operation. Surgery 1964;56:151-7.

9. Kachroo S, Dao T, Zabaneh F, Reiter M, LaRocco MT, Gentry LO, Garey KW. Infectious Diseases: Tolerance of Vancomycin for Surgical Prophylaxis in Patients Undergoing Cardiac Surgery and Incidence of Vancomycin-Resistant Enterococcus Colonization. Annals of Pharmacotherapy. 2006 Mar;40(3):381-5.

10. Wagenlehner F, Stöwer-Hoffmann J, Schneider-Brachert W, Naber KG, Lehn $\mathrm{N}$. Influence of a prophylactic single dose of ciprofloxacin on the level of resistance of Escherichia coli to fluoroquinolones in urology. International journal of

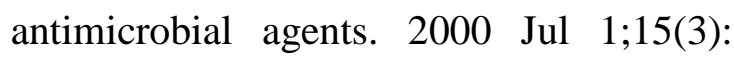
207-11.

11. Martin C. Antimicrobial prophylaxis in surgery: general concepts and clinical guidelines. Infection Control \& Hospital Epidemiology. 1994 Jul;15(7):463-71.

12. Chambers HF. Betalactam antibiotics and other antibiotics of cell wall synthesis. In: Katzung BG, editor. Basic of Clinical 
Pharmacology. 8th ed. New York: Lange Medical Books, McGraw-Hill; 2001. p. 762.

13. Woods RK, Dellinger EP. Current guidelines for antibiotic prophylaxis of surgical wounds. Am Fam Physician 1998;57:2731-40.

14. Classen DC, Evans RS, Pestotnik SL, Horn SD, Menlove RL, Burke JP. The timing of prophylactic administration of antibiotics and the risk of surgical-wound infection. New England Journal of Medicine. 1992 Jan 30;326(5):281-6.

15. Fernandez Arjona M, Herruzo Cabrera R, Gomez-Sancha F, Nieto S, Rey Calero J. Economical saving due to prophylaxis in the prevention of surgical wound infection. Eur J Epidemiol 1996;12:455-9.

16. Akhtar S, Gondal KM, Ahmed M, Mohammad Y, Goraya AR, Karim F, Chaudhry AM. Surgical Wound Site Infection-our experience. Annals of King Edward Medical University. 2017 Oct 26;7(3).

17. leaper D .J. wound infection . In : Russell R .C., Williams N S., Bulstrode C J. editors. Bailey and love's short practice os surgery. $23^{\text {rd }}$ ed. London: Arnold, 2000:8798. 